\title{
DO DIREITO DA LIBERDADE À SOLIDARIEDADE
}

\author{
Anderson Alencar de Menezes ${ }^{1}$ \\ Universidade Federal de Alagoas (UFAL).
}

Dalmo Cavalcante de Moura ${ }^{2}$

Faculdade São Tomás de Aquino (Facesta)

modal.moura@gmail.com

\begin{abstract}
Resumo
O trabalho aborda o tema Solidariedade com base formulações do filosofo alemão da Teoria Crítica chamado Axel Honneth. Apresenta, sob a perspectiva de Axel Honneth, o desenvolvimento do papel da justiça social como análise da sociedade. Aponta a ocorrência dos movimentos sociais como iniciativas para interpretar as experiências de desapontamento pessoal e como algo que afeta não só o eu individual, mas também o círculo de muitos outros sujeitos. Traz à tona o papel desses movimentos em uma perspectiva crítico-normativa que consiste em fornecer um padrão para identificar as patologias sociais e avaliar os movimentos sociais (seu caráter emancipatório ou reacionário), para distinguir a função que desempenham para o estabelecimento de um progresso moral na dimensão do reconhecimento.
\end{abstract}

Palavras-chave: Liberdade. Solidariedade. Axel Honneth.

\begin{abstract}
The paper approaches the theme Solidarity based on formulations of the German philosopher of Critical Theory called Axel Honneth. It presents, from the perspective of Axel Honneth, the development of the role of social justice as an analysis of society. It points to the occurrence of social movements as initiatives to interpret the experiences of personal disappointment and as something that affects not only the individual self, but also the circle of many other subjects. It brings to the fore the role of these movements in a critical-normative perspective, which consists in providing a pattern for identifying social pathologies and evaluating social movements (their emancipatory or reactionary character) to distinguish their role in establishing moral progress in the dimension of recognition.
\end{abstract}

FROM THE RIGHT OF FREEDOM TO SOLIDARITY

Keywords: Freedom. Solidarity. Axel Honneth.

\footnotetext{
${ }^{1}$ Formado em Licenciatura em Filosofia pela Universidade Católica de Pernambuco, Bacharel em Teologia pelo Centro Unisal, Campus Pio XI (São Paulo), Mestre em Filosofia pela Universidade Federal de Pernambuco e Doutor em Ciências da Educação pela Universidade do Porto/Portugal. Atualmente é professor da Universidade Federal de Alagoas (UFAL). Coordenador do Grupo de pesquisa Teoria Crítica: Emancipação e Reconhecimento (TECER) e membro do grupo de pesquisa Filosofia e Educação e Ensino de Filosofia (UFAL).

${ }^{2}$ Formado em Licenciatura em Filosofia pela Universidade Federal de Alagoas (UFAL). Mestre em Educação Brasileira pela Universidade Federal de Alagoas (UFAL), Atualmente exerce a função de professor do curso de Licenciatura da Facesta (Faculdade São Tomás de Aquino). Membro do Grupo de pesquisa Teoria Crítica: Emancipação e Reconhecimento.
}

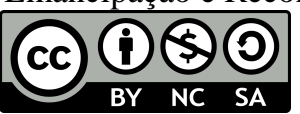

P2P \& INOVAÇÃO, Rio de Janeiro, v. 5 n. 2, p.10-23, Mar./Ago. 2019. 


\section{A HISTORICIDADE DO DIREITO DA LIBERDADE}

O tema da Solidariedade na atualidade é muito instigante, tendo em vista os acontecimentos atuais que estamos presenciando na Europa e em outros continentes, a assim chamada crise dos imigrantes ou crise humanitária tem várias denominações.

Nossas colocações acerca do tema da Solidariedade estão baseadas nas formulações do filosofo alemão da Teoria Crítica chamado Axel Honneth (1949)³.

Pensamos este texto a partir da concepção de Liberdade proposta por Honneth na obra: O Direito da Liberdade (2015). Essa obra foi publicada inicialmente em 2011 em Berlim na Alemanha. Essa obra foi formulada durante 5 anos de estudo. A discussão se desenvolve tendo como base conceitual a contribuição de $\mathrm{Hegel}^{4}$ e sua Filosofia do Direito. A pretensão de Honneth é desenvolver a justiça social como análise da sociedade. Assim, como o pensamento de Hegel a questão dos valores da sociedade liberal-democráticas está no valor que consegue unir todos os outros, a Liberdade.

Dessa forma, toda a pretensão de discutir justiça social passa obrigatoriamente pela questão da liberdade. É a liberdade que assegura o mínimo de um comportamento reciproco que permite uma maneira justa de convivência (solidária).

Para que a liberdade seja realizada, Honneth (2015, p. 10), diz: “[...] uma vez que para a realização da prometida liberdade, são sempre necessárias precondições sociais especiais e considerações recíprocas entre os indivíduos".

Como se deu a compreensão histórica da liberdade institucionalizada na realização social na sociedade moderna e atual? O que é mesmo uma teoria da justiça como analise da sociedade?

Uma das grandes carências da filosofia política atual aponta Honneth (2015) é que as análises da liberdade não estão relacionadas com a análise da sociedade. Nesse sentido, as análises passaram a ser apenas normativas. Essa maneira de tratamento conceitual, não favorece a interpretação da eticidade prática e institucional. Portanto, há uma aporia de como é e como deveria ser essa análise da sociedade atrelada a análise da liberdade.

A interpretação da obra Filosofia do Direito de Hegel foi marcada por duas concepções. Uma primeira num sentido de uma doutrina da restauração conservadora. A segunda como uma teoria da revolução. Esse é o debate contemporâneo acerca do pensamento hegeliano de sua

\footnotetext{
${ }^{3}$ Filósofo, sociólogo e professor nascido na Alemanha na cidade de Essen em 1949. Desde 2001 é diretor do Institut für Sozialforschung (Instituto para Pesquisa Social), também conhecido como Escola de Frankfurt.

${ }^{4}$ Georg Wilhelm Friedrich Hegel Filósofo alemão nascido em Estugarda em 1770 e falecido em 1831. Fundador do sistema filosófico conhecido como Idealismo Alemão.
} 
época, ou seja, a conhecida diferença entre hegelianos de direita e hegeliano de esquerda. Aqui não temos a pretensão de alongar essas especificidades. No contexto das discussões da teoria do direito de Hegel foi afastada a concepção revolucionária e ficou mais presente a questão da legitimidade moral das instituições. Esse imperativo tem relação com o contexto alemão da monarquia defendida por alguns intelectuais alemães, entre eles Hegel.

Como podemos perceber até agora existe duas problematizações presente nessa discussão até aqui colocadas. Uma a preocupação excessiva na normatividade, e outra o esquecimento total das instituições.

É o projeto hegeliano que Honneth (2015) pretende trazer à tona e rediscuti-lo conosco. Tendo em vista que Hegel em sua Filosofia do direito conseguia fazer uma unidade entre as instituições de sua época e a racionalidade moral como realização da própria modernidade. Hegel (Honneth, 2015) então procura dá nomes a tudo o que aparece na realidade social e que tinham de alguma forma legitimidade moral para possibilitar a tão almejada universalidade hegeliana e a liberdade individual, categoria tão cara a modernidade. É grande a pretensão de Honneth, já que a sociedade da qual Hegel fazia parte é muito diferente na atualidade, tanto na prática quanto na facticidade moral. O contexto hegeliano é marcado por uma sociedade constitucional-monarquista do início do processo de industrialização. As instituições, estruturas e organização as quais Hegel depositou estabilidade na busca pela sua universalidade sistêmica, foram transformadas, perderam sua forma original, para Honneth (2015, p.18):

\footnotetext{
Além disso, a experiência de uma "quebra da civilização", isto é, a presentificação da possibilidade do holocausto em meio a sociedade civilizadas, acrescentou um decisivo freio nas esperanças que Hegel ainda podia depositar no desenvolvimento continuo e contido nos parâmetros da razão nas sociedades modernas.
}

A tentativa de Honneth (2015) em enfrentar essa problemática estão baseadas em três premissas. A primeira premissa tem uma relação com a questão de que a reprodução da sociedade está ligada à condição de uma orientação comum por ideias e valores que são a base. Tais normas éticas determinam de cima quais são as medidas ou desenvolvimentos sociais que podem ser considerados. Tais normas também podem ser determinadas por baixo, ou seja, como objeto de educação mais ou menos institucionalizados, pelos quais em fim se organiza a vida dos indivíduos dentro da sociedade. Porém esse ordenamento não explica por completo toda as formas de vida aprovadas ou proibidas.

Portanto, há uma tensão entre os valores éticos específicos que devem se tornar mais abrangentes e gerais, podendo até integrar as culturas minoritárias, segundo Honneth (2015, p. 21): "Em sentido semelhante, que de início é um sentido meramente fraco, toda sociedade é, 
em certa medida, uma encarnação do espírito objetivo, porque suas instituições, porque suas instituições, suas práticas e rotinas sociais refletem convicções cooperativa".

A segunda premissa é a proposta que problematiza os valores ou ideais como ponto de referência moral de uma justiça. Enquanto pretensões normativas, a um só tempo constitui reivindicações normativas e condições de reprodução de cada sociedade. Para muitos autores, a justiça não é algo em si mesmo, só pode ser explicada em relação a outras categorias. Portanto, a justiça não é autônoma.

Tais padrões normativos só podem ser aplicados posteriori, pois, acontece a partir da: Qualidade moral, instituições e práticas. Sendo assim, o pensamento Honnethiano busca em seu pensamento retomar a Filosofia do Direito de Hegel.

Retomando a questão tão cara a Teoria Crítica de reconstrução das análises, tendo como parâmetro a modernidade. Mas o que então é uma reconstrução normativa? Segundo Honneth (2015, p. 24):

Por "reconstrução normativa" entende-se o processo pelo qual se procura implantar as intenções normativas de uma teoria da justiça mediante a teoria da sociedade, já que valores justificados de modo imanente são, de maneira direta, tomados como fio condutor da elaboração e classificação do material empírico.

Portanto, à medida que as instituições e práticas são essenciais para a compreensão da materialização e realização de valores socialmente legitimados são essenciais ao entendimento da sociedade. É preciso, tomar o conjunto das rotinas e instituições sociais, escolhendo as que são indispensáveis a reprodução social.

A terceira premissa tem a preocupação de buscar validar o procedimento metodológico de reconstrução que é normativa. Nesse sentido, é preciso pressupor que a realidade nunca está dada por si mesma. Pensando dessa forma, as concepções de sociedades das Ciências Sociais estão distantes da realidade da sociedade contemporâneas. De antemão, é necessário definir o que é importante e o que fica em segundo plano para explicar a sociedade.

Nesse desenvolvimento de explicações, o conceito de "eticidade" (sitlichekeit) de Hegel foi esquecido, desacreditado após a morte dele. Claro que o pensamento hegeliano, busca a universalidade das várias formas de vida ética, na tentativa de explicar a universalidade do movimento da modernidade.

A quarta premissa é a tentativa de desenvolver uma teoria da justiça como uma forma de análise da sociedade que deve esta pressuposta não só o procedimento da reconstrução normativa, mas críticas as várias estâncias da eticidade. Para Honneth (2015), Hegel aponta a decadência ética, já que as corporações não cumprem suas atividades de maneira plena. A 
sociedade que Hegel presenciou a relação de consumo ostensivo não integrava a todos os cidadãos. Isso revela um sistema desintegrador, divisório dentro do sistema de guildas.

Para concluir esse quadro geral. A primeira premissa. Tanto os objetivos da reprodução social quanto a integração cultural são regulados por normas, enquanto bem maior coletivo. A segunda premissa. Todo conceito de justiça implica a aceitação dos valores nas práticas e instituições da sociedade.

A terceira premissa está relacionada a questão de que a diversidade da realidade social, são aceitos e selecionados em termos metodológicos ou reconstrutivo normativamente para assegurar os valores universas.

\section{O DIREITO À LIBERDADE E À SOLIDARIEDADE EM HONNETH}

Nesse tópico iremos traçar as linhas gerais do Direito da Liberdade. Honneth (2015), faz a reconstrução da liberdade levando-se em conta a historicidade dela.

A Liberdade é a categoria ou direito que nasce da modernidade e que serve para caracterizar o ordenamento institucional da sociedade que vai assegurar a liberdade, enquanto autonomia da individualidade.

É impossível articularmos uma relação de estudo da modernidade sem passar pela questão da compreensão da autonomia individual. Essa é uma questão basilar de qualquer estudo sério acerca da modernidade. Pode-se atribuir qualquer coisa para esse alcance tais como: o ordenamento natural, a voz interior e o louvor da autenticidade na modernidade, mas todos esses pressupostos vão levar a autonomia individual.

Esse imperativo da autonomia individual da modernidade produz uma associação sistêmica entre o si mesmo individual e o ordenamento social. Essa ideia de liberdade na modernidade para Honenth (2015), é articulada com duas grandezas de referências: A representação do que é bom para o indivíduo e o ordenamento social.

Na modernidade a capacidade de autodeterminação é se altera na relação de que as regras de convívio social; e sua legitimidade depende da legitimidade normativa representada. $\mathrm{Ou}$ essa autodeterminação individual expressa a soma das individualidades ou realiza adequadamente seus pressupostos. Segundo Honneth (2015, p. 36): "Então, o princípio da autonomia individual já não se separa da ideia de justiça social e das reflexões sobre como ela deve ser instituída na sociedade para tornar justos os interesses e necessidades de seus membros". 
Foi preciso muito esforço e estudo para mostrar que as perspectivas pós-modernas de justiça e autonomia individual é uma forma aprimorada daquela mesma da modernidade. As fronteiras biológicas, origem e culturais não servem mais como argumentos para a justiça. $\mathrm{O}$ feminismo, os movimentos trabalhistas, os combatentes da Civil Rights Movement, todos combateram as formas jurídicas e sociais de desrespeito. Na sociedade moderna a exigência de justiça implica a autonomia da referência individual.

Essa relação entre justiça e liberdade individual é antes de qualquer coisa a fusão de dois conceitos resultado de um longo processo de aprendizado recessivo.

Dessa forma, podemos afirmar que a justiça é entre outras coisas a nossa capacidade de subjetivação de justiça. O espírito humano para Honneth (2015), se pergunta pela justiça como ponto de validação das regras e normas às quais a vida comum está determinada a obedecer. $\mathrm{O}$ que seria o justo nessa problemática? $\mathrm{O}$ justo é o que garante a proteção, o incentivo e a realização da autonomia de todos os membros da sociedade, segundo Honneth, $(2015$, p. 41):

\begin{abstract}
No curso desse debate, ficou claro que com a ideia de liberdade propaga-se sempre a imagem que modifica a ideia metodológica de justiça: uma ampliação de tudo aquilo que deve pertencer ao "eu" da autodeterminação individual altera não apenas os fundamentos de conteúdo, mas também as leis de construção do ordenamento justo, pois, quanto mais faculdades e condições são consideradas necessárias para de fato possibilitar a autonomia do indivíduo, com tanto mais força a perspectiva daqueles para os quais deverão valer esses princípios deverá se integrar no estabelecimento dos princípios.
\end{abstract}

A modernidade fundamentou em seu discurso moral três modelos distintos para os conflitos com a liberdade. Portanto, falar em liberdade na modernidade para Honneth (2015), requer primeiro, uma reconstrução partindo primeiro, segundo um modelo reflexivo e um modelo social; terceiro compreender a liberdade como positiva e negativa.

A solidariedade na nossa reflexão tem relação com essas implicações acerca da liberdade. Essa questão é bem problemática, já que estamos diante de uma concepção que o indivíduo em si mesmo não tem a capacidade de se autorrealizar, já que esse mesmo indivíduo autêntico só consegue se expressar dentro de uma comunidade social, ou seja, ele só consegue se desenvolver como liberdade reflexiva no coletivo.

A concepção de justiça que traz a ideia de autorrealização assumi diferentes formas e metodologicamente condicionada e compreender o ordenamento social como uma materialização das ações nas quais os sujeitos realizam as intenções compartilhadas. As discussões públicas enquanto deliberações podem ser compreendida como forma coletiva de autorrealização. 
Nesse sentido para Honneth (2015), toda a justiça só pode ser feita através dos arranjos institucionais que permitem a solidariedade. A solidariedade é necessária à cidadania, como aquilo que é "justo" e que garante a atividade comum no espaço público.

Qual é a importância da solidariedade? É através dela que a sociedade mantém e estimula a igualdade e a inclusão social de todos sem distinções. A filosofia moral conceituou a obrigação familiar era definida como formas de obrigações, amizade e afeto. Essa concepção está centralizada numa análise a partir de papeis ou deveres. Na atualidade as obrigações morais não podem ser consideradas naturais ou teorias da amizade. A análise dessa problemática para Honneth (2015), deve ser atrelada a questão essencial da intersubjetividade. Para além da obrigação, do sentimento mútuo. O que tem de nessa possibilidade de explicação? O modelo burguês da modernidade sofreu alterações que precisam ser demonstradas. Em razão da divisão do trabalho, houve uma transformação e decadência dos papeis fixos antes posto por meios de padrões. Na atualidade os padrões são mais flexíveis. A força da família moderna está nessa imposição exterior que ao mesmo tempo em que fortalece também enfraquece, já os padrões na atualidade não são fixos. $\mathrm{O}$ afeto se tornou informal e livre.

Nesse contexto no pensamento de Hegel já há uma preocupação com a questão da relação dos cálculos dos lucros na sociedade que se torna proveitosos apenas quando os sujeitos reconhecem juridicamente os seus parceiros contratuais formando uma comunidade cooperante. Sem essa solidariedade não há possibilidade do reconhecimento do contrato estabelecido entre os sujeitos e a sociedade, segundo Honneth (2015, p. 340):

\footnotetext{
Assim, como todas as demais esferas sociais, o mercado também necessita do assentimento moral de todos os participantes que atuam nele, de modo que suas condições de constituinte não possam ser descritas de maneira independente das normas que o complementam, as quais são, da perspectiva daqueles, as únicas a lhe conferir legitimidade.
}

Honneth (2015), vai discutir essa relação da moral e da economia de maneira mais profunda. $\mathrm{O}$ que isso implica afinal? Que os sujeitos do trabalho não estão desarticulados do mundo do trabalho e que esse mesmo mundo é marcado também entre outras coisas com os “imperativos extraeconômicos” (Honneth, 2015, p. 348).

O questionamento será dado na discussão de Marx entre a problemática daqueles que no mercado de trabalho, só tem uma mercadoria a "força de trabalho".

Portanto, o contrato entre os sujeitos e os donos dos meios de produção, nunca foram igualitários, segundo Honneht (2015, p. 366):

Desse modo, a questão aqui em debate assume traços empíricos; não é possível decidir de antemão se no interior das economias de mercado capitalista é possível estabelecer as condições sociais de uma liberdade geral de contrato, mas isso precisa ser revisado num processo de reformas implementadas com esse propósito. 
No desenvolvimento do século XIX aconteceu a construção gradual de uma política social do Estado. Praticamente todos os países liberais da Europa Ocidental fizeram essa política, ela é resultado das tensões existentes no movimento operário.

Assim, surge por parte do Estado proposta de assistência social, tendo em vista a necessidade de criar uma Solidariedade Social. Com as crescentes crises do sistema capitalista o Estado passou a se preocupar com os pobres, lembrando que tais lutas também eram parte das associações de militares da Europa que já tinham passado por duas grandes guerras.

Os países como Inglaterra, França, Suécia, Áustria e Alemanha foram obrigados a criar muitas leis de seguridade social e proteção da classe trabalhadora e reprimindo assim os interesses das empresas capitalistas. As medidas tomadas tinham o caráter de pacificar e controlar as elites políticas, as associações empresárias e os movimentos dos trabalhadores. A institucionalização dessas políticas sócio-econômica exige a igualdade de oportunidade e criação de meios discursivos para estabelecer um diálogo e a Solidariedade. Como podemos perceber o Estado tornou-se solidário as questões dos mais pobres e trabalhadores: horários fixos, pagamentos de indenizações, proteção contra acidentes, são algumas das inovações desse debate entre Estado e solidariedade institucionalizada.

Essa rede de solidariedade também se deve ao momento histórico do pós-guerra, apesar de alguns avanços só depois de 1929 até então os direitos sociais eram muitos rudimentares e precários. No pós-guerra os movimentos dos trabalhadores europeus pediam essa tomada de decisão a favor da liberdade social e solidariedade.

Uma questão bem atual que Honneth (2015), nos traz é a preocupação de Durkheim em seu tempo já recomendava um "patriotismo constitucional" como proposta para afastar o risco de um nacionalismo agressivo. Essa consideração de Durkheim se torna mais atual do que nunca, tendo em vista a sobrevivência das democracias ocidentais. Nesse contexto, os imigrantes já naquela época colocavam em discussão a cultura da maioria, tinha que levar em conta agora o multiculturalismo.

Assim, esse ambiente de solidariedade cidadã se articula com as formas de vida permitindo a formação de uma cultura consciente dos cidadãos, segundo Honneth (2015, p. 561):

Nos dias atuais, em razão da pluralidade que sobreveio às formas de vida, essa base nacional da solidariedade cidadã está se dissolvendo, e assim iniciou-se um movimento de busca, em parte bizarro, em parte produtivo, podem preservar a coesão cultural dos cidadãos. 
A ideia de patriotismo constitucional que Honneth (2015), ainda carece de atração afetiva para que possa um dia valer como alternativa para alcançar o Estado Nacional da Solidariedade Cidadã. Portanto, falta á concreção histórica, um relato histórico de êxito e fracassos para que os cidadãos possam entender o sentido e o destino da comunidade da cidadania democrática.

O que Honneth (2015), revela é a mudança das funções do pertencimento nacional ao Estado-nação individual para a criação do reconhecimento como base na confiança e solidariedade e atenção aos campos de ação moralmente sensíveis as liberdades do indivíduo. Talvez a falta de união da Europa em um projeto único na atualidade seja resultado da falta desse entendimento mútuo de reconhecimento.

O que tentamos fazer aqui foi remontar o Direito da Liberdade e a relação com a solidariedade. O tema é bem instigante e exige aprofundamento de questões da tradição da filosofia política e a historicidade da Liberdade.

\section{PADRÕES DE RECONHECIMENTO INTERSUBJETIVO: AMOR, DIREITO E SOLIDARIEDADE}

Em relação às questões da Gramática Moral dos Conflitos Sociais e das teses sobre Reconhecimento e Justiça, partimos das ideias de Denilson Luis Werle e Rúrion Soares Melo expressas no artigo Reconhecimento e Justiça na Teoria Crítica da Sociedade em Axel Honneth, parte da obra, Curso Livre de Teoria Critica, organizada por Marcos Nobre.

Inspirando-se na ideia hegeliana de luta por reconhecimento, Honneth procura fundamentar uma versão própria da Teoria Crítica e, com isso, elabora uma concepção audaciosa da mudança e da evolução social, com base na relação ameaçada entre identidade pessoal e coletiva que luta por reconhecimento e propõe uma concepção normativa da vida boa - uma concepção formal de eticidade. Seria uma teoria social com teor normativo. A preocupação de Honneth (2009), está em fazer um aporte numa dupla perspectiva:teóricoexplicativa ecrítico-normativa.A perspectiva teórico-explicativa é a de dar conta da "gramática" dos conflitos e da "lógica" das mudanças sociais, tendo em vista o objetivo mais amplo de "explicar a evolução moral da sociedade”. A perspectiva crítico-normtativa consiste em fornecer um padrão para identificar as patologias sociais e avaliar os movimentos sociais (seu caráter emancipatório ou reacionário), para distinguir a função que desempenham para o estabelecimento de um progresso moral na dimensão do reconhecimento. 
Analisando os textos do jovem Hegel, Honneth (2009), destaca a ideia fundamental de que os indivíduos só podem se formar e constituir suas identidades pessoais quando são reconhecidos intersubjetivamente. O indivíduo só pode ter uma relação positiva consigo mesmo se for reconhecido pelos demais membros da comunidade.

Quando o Reconhecimento não é bem-sucedido (pela ausência ou falso reconhecimento), desdobra-se uma luta por reconhecimento na qual os indivíduos procuram restabelecer ou criar condições de reconhecimento recíproco. Ao contrário de Maquiavel e Hobbes, para os quais os conflitos sociais são explicados por lutas de auto conservação, para Honneth (2009), seguindo a interpretação de Hegel, a luta social tem uma gramática moral. Os escritos de juventude de Hegel fornecem o maior potencial de inspiração para a reconstrução do conceito de uma luta moralmente motivada.

São três as dimensões do Reconhecimento:

1) Primeira Dimensão: abrange as relações primárias, ligadas à experiência do amor e da amizade e fazem parte da esfera emotiva. Tal esfera permite ao indivíduo desenvolver uma confiança em si mesmo, indispensável para seus projetos de auto-realização;

2) Segunda Dimensão: abrange as relações jurídicas próprias do campo do "direito". Essa esfera jurídico-moral assegura aqueles direitos que permitem que a pessoa seja reconhecida como autônoma e moralmente imputável, possibilitando assim o desenvolvimento dos sentimentos de auto-respeito;

3) Terceira Dimensão: abrange a solidariedade social. Para além da autoconfiança e do sentimento de auto-respeito, essa dimensão abrange a esfera da estima social, em que os projetos de realização pessoal podem ser objeto de um respeito solidário numa comunidade de valores.

Honneth (2009), citando Mead, em sua Psicologia Social refere-se a três Formas de Reconhecimento: Dedicação Emotiva: relações amorosas e relações de amizade; Reconhecimento Jurídico; Assentimento Solidário. Quando se fala de AMOR entende-se as relações primárias, ou seja: relações eróticas entre dois parceiros, relações de amizades e relações entre pai/filho.

Para Hegel (1991), o amor designa mais do que o relacionamento sexualmente preenchido entre homem e mulher. Neste sentido, o amor representa a primeira etapa de Reconhecimento recíproco. Os sujeitos se confirmam mutuamente na natureza concreta de suas carências. Há uma experiência recíproca de dedicação amorosa. O próprio Reconhecimento deve possuir aqui o caráter de assentimento e encorajamento afetivo (sentimentos de estima 
social). A chave hegeliana desta representação é conceber o Amor como um "ser-si-mesmo em um outro".

Honneth (2009), procura mostrar que o indivíduo desenvolve, em cada forma de reconhecimento, um tipo de relação prática positiva consigo mesmo (a autoconfiança nas relações amorosas e de amizade; o auto-respeito nas relações jurídicas e a auto-estima na comunidade social de valores), ressaltando os vínculos entre liberdade e autonomia individual e os vínculos comunitários/societários. A ruptura ou violação dessas condições gera formas de desrespeito social que levam a lutas sociais e conflitos políticos motivados por diferentes razões morais.

A cada uma das formas de reconhecimento corresponde uma forma de desrespeito: maustratos e violação, que ameaçam a integridade física e psíquica, em relação à primeira; privação de direitos e exclusão, que atingem a integridade social do indivíduo como membro de uma comunidade político-jurídica, na segunda; e degradação e ofensas, que afetam os sentimentos de honra e dignidade do indivíduo como membro de uma comunidade cultural de valores, no caso da terceira esfera de reconhecimento. Cada uma delas abala de modos diversos a autorelação prática da pessoa, privando-a do reconhecimento de determinadas dimensões de sua identidade.

Para Honneth (2009), interessam aqueles conflitos oriundos de experiências de desrespeito social capazes de suscitar uma ação de luta social que busque restaurar as relações de reconhecimento mútuo ou desenvolvê-las num nível de ordem superior. É possível ver na luta por reconhecimento uma força moral que impulsiona desenvolvimentos sociais, políticos e institucionais.

São as lutas moralmente motivadas de grupos sociais, sua tentativa coletiva de estabelecer institucional e culturalmente formas ampliadas de reconhecimento recíproco, aquilo por meio do qual vem a se realizar a transformação normativamente gerida das sociedades.

O que importa mostrar é a lógica dos conflitos que se originam de uma experiência social de desrespeito, de uma violação da identidade pessoal ou coletiva.

Os conflitos sociais emanam de experiências morais decorrentes da violação de expectativas normativas de reconhecimento firmemente arraigadas. Essas expectativas formam a identidade pessoal. Quando essas expectativas são desapontadas, surge uma experiência moral que se expressa no sentimento de desrespeito. O sentimento de desrespeito, por sua vez, somente pode se tornar um ponto de vista generalizável, dentro do horizonte normativo de um grupo. 
O surgimento de movimentos sociais depende da existência de uma semântica coletiva que permita interpretar as experiências de desapontamento pessoal como algo que afeta não só o eu individual, mas também o círculo de muitos outros sujeitos. A sequência desrespeito, luta por reconhecimento e mudança social constitui o desenvolvimento lógico dos movimentos coletivos. Em síntese, a ideia básica é a de que sentimentos morais, quando articulados numa linguagem comum, podem motivar as lutas sociais.

Segundo Honneth (2009), existem formas não distorcidas de reconhecimento. No âmbito da dinâmica social do reconhecimento, do desrespeito e da luta por reconhecimento pode ser extraída uma concepção formal de eticidade ou vida boa que sirva como padrão normativo de justificação da normatividade.

Nas sociedades modernas, os sujeitos têm de encontrar reconhecimento como seres tanto autônomos quanto individualizados. A concepção formal de eticidade reúne todos os pressupostos intersubjetivos que precisam estar preenchidos para que os sujeitos se possam saber protegidos nas condições de sua auto-realização.

Honneth (2009), em sua obra Luta por Reconhecimento, ao retomar o jovem Hegel (1991), de Jena fala da ideia de uma Fenomenologia das Relações de Reconhecimento; ao citar o psicanalista inglês Donald Winnicott apresenta o conceito de Fase de Intersubjetividade Indiferenciada em oposição à teoria freudiana do narcisismo primário. Winnicott fala de uma Intersubjetividade Primária que constitui o processo de interações sociais através do qual mãe e filho podem se separar do estado de indiferenciado ser-um, de modo que eles aprendem a se aceitar e amar, afinal, como pessoas independentes. Segundo Winnicott há um processo de amadurecimento infantil que comporta uma cooperação intersubjetiva mãe/filho.

Seja, no estado de ser-um simbiótico, eles de certo modo precisam aprender do respectivo outro como eles têm de diferenciar-se em seres autônomos. A mãe e a criança podem saber-se dependentes do amor do respectivo outro, sem terem de fundir-se simbioticamente uma na outra.

Concluímos com Winnicott acerca do processo de amadurecimento na primeira infância com ilações a respeito da estrutura comunicativa que faz do Amor uma relação particular de reconhecimento recíproco.

Na interpretação de Honneth (2009), para Winnicott, a quebra da simbiose faz surgir aquela balança produtiva entre delimitação e deslimitação, que para ele pertence à estrutura de uma relação amorosa amadurecida pela desilusão mútua (tensão intersubjetiva; relação descontraída consigo). 
Na compreensão de Honneth (2009), para Hegel, a forma do Reconhecimento do Amor que ele descreve como um "ser-si-mesmo em um outro" não designa um estado intersubjetivo, mas um arco de tensões comunicativas que medeiam a experiência do poder-estar só com a do estar-fundido.

A referencialidade do "eu" e a Simbiose representam os contrapesos exigidos mutuamente e que possibilitam estar-consigo mesmo no outro. A Reciprocidade da estrutura intersubjetiva tensa é perturbada nos casos patológicos ou pela autonomia egocêntrica ou pela dependência simbiótica. Nesse sentido, salienta-se a ideia de aceitação cognitiva da autonomia do outro e o Reconhecimento da independência do outro. 


\section{REFERENCIAS}

HEGEL, G. W. F. O sistema da vida ética. Lisboa: Edições 70, 1991.

HONNETH, A. Luta por reconhecimento: a gramática moral dos conflitos sociais. 2. ed. São Paulo: Editora 34, 2009.

HONNETH, A. O direito da liberdade. São Paulo: Martins Fontes, 2015.

NOBRE, M. (org). Curso livre de teoria crítica. Papirus: Campinas, 2008. 